\title{
Palm Method
}

National Cancer Institute

\section{Source}

National Cancer Institute. Palm Method. NCI Thesaurus. Code C154793.

A method for estimating body surface area, in which the individual's palm, excluding fingers and wrist, accounts for about $0.5 \%$ of the total body surface area of that individual. The entire palmar surface (including fingers) accounts for about 1\% of the individuals total body surface area. 